\title{
Onweonye: Introducing the Concept of Self-Personhood in Igbo Ontology
}

\author{
Chika John Bosco Gabriel Okpalike \\ Department of Religion and Human Relations, Faculty of Arts, Nnamdi Azikiwe University, Awka, Nigeria
}

\section{Email address:}

cg.okpalike@unizik.edu.ng

\section{To cite this article:}

Chika John Bosco Gabriel Okpalike. Onweonye: Introducing the Concept of Self-Personhood in Igbo Ontology. International Journal of Philosophy. Vol. 8, No. 4, 2020, pp. 88-97. doi: 10.11648/j.ijp.20200804.12

Received: October 27, 2020; Accepted: November 7, 2020; Published: November 24, 2020

\begin{abstract}
Faced with an unprecedented and challenging socio-political situation at home (Nigeria), the Igbo struggle for survival and relevance throughout the world has taken various forms in the last five decades. Industry, commerce, education, invention/innovation have been undertaken together with an unprecedented spate of emigration, which has seen the Igbo everywhere in the world. The Igbo, wherever they may be found, stop at nothing, unleashing their potentials in a virile, resilient and competitive spirit which they have come to be known for through time. Even in diaspora, the Igbo understand their Igbo fellows as the stiffest competitors and strive to outdo each other. As a result, the Igbo have been understood by others as selfish and even among the Igbo, there is the unfortunate misconstrue of such as hate, selfishness and individualism. Inversely, these socio-ethical images of the Igbo are antithetical to the content of traditional Igbo morality which is characterized by conviviality and community. This research builds on the nature, being, becoming and existence of the Igbo individual. Evidently, the individual among the Igbo is at the heart of Igbo existence; the attainment of which is a lifetime struggle. The Igbo individual like the Igbo universe is fluid; its reach and positive impact among the Igbo speak its quality and relevance. In its fluidity, it is becoming; in its reach, it spans beyond earthly existence; in its impact, it is community-oriented. This ontology will give insight into the Igbo socio-economic engagements wherever they may be found. The research employs the tools of Igbo cultural institutions, rites of passage and entelechy of human struggles to offer a robust perspective for understanding the selfless and altruistic nature of the Igbo individual which is the ultimate attainment of that individual, viewed in this work through the prism of Onweonye. The research employs the technique of documentary hermeneutics and analysis combined with in-depth library research method of inquiry into the complex composition of the individual in Igbo ethnography and ontology.
\end{abstract}

Keywords: Onwe, Onye, Personhood, Selfhood, Igbo Ontology, Ontology, Igbo Cosmology, Onweonye

\section{Introduction}

Studies in Igbo humanities are developing and are becoming increasingly existential in orientation. The pioneering works of Francis Arinze [1], Emmanuel Ifesieh [2], Emefie Ikenga Metuh [3] and others in Igbo cosmology which contained a lot of hermeneutics and analysis of Igbo world view and concepts had inspired the likes of Bona Umeogu [4], Celestine Mbaegbu [5] and many others to undertake elaborate exercise in Igbo ontology that have come a long way in African humanities. More recently, research in Igbo humanities are taking existentialist bend which is the area of interest in the present work. On the other hand, the socio-political situation in Nigeria and the perceived marginalization and persecution of the Igbo in the scheme of things complicated by a new religious wave, which has aided turning the pristine Igbo culture and beliefs on its head, have made such studies both more interesting and curious at the same time. In the new religious consciousness referred to above, traditional worship spaces have been destroyed, blood and family ties severed and wholesale bad blood and ill-feelings among folks unleashed. However, several of these studies referred to, had explored the Igbo from within and without (as a section of the many Nigerian ethnic nationalities or the larger African continent). Very often, Igbo existentialism had been explored in themes like language dearth (the kind which was undertaken by Emma Asonye [6]), social stigmatization (Segun Akande had among his five characterizations of the Igbo included that they are a domineering tribe [7]), economic strangulation (represented in 
the opinion of Segun Adebowale [8]), political marginalization (decried by the likes of Ezeakukwu Emmanuel Nsoedo [9]), moral decadence (seen in the work of Onyema Sunday Iherue [10]), religious inclinations (studied by Chinwe M. A. Nwoye [11]) and leadership problems (Dotun Ibiwoye had quoted Senator Ben Obi capturing the essence of leadership among the Igbo thus: "I am not looking up to anybody to emerge as an Igbo leader, because Igbo are big and they don't have leaders. Leadership in Igbo land is more of a collective thing." [12]). These studies also are mostly conducted with the empirical method of data collection and analysis. In spite of the depth of information often contained in such works, they may present as problematic in two ways.

First, they do not represent the ontological foundations of the patterns they study. They only deal with empirical and observable data to evaluate prevalence, influence, occurrence etc. As a result, since what is extrinsically observable about a thing, may offer little or no information about the intrinsic dynamics of its being, there remains a gap in the comprehensive representation of being Igbo. This writer agrees with one of the ideas of David Lewis about the relationship between intrinsic and extrinsic properties, in which he declares that the intrinsic is the exact unshared property whereas the extrinsic is dynamic and related to the environment of manifestation more than the thing itself. [13] In other words, the intrinsic property which is the ontological character of the thing is its exact nature. For instance, the observable constant and stiff competition and rivalry among the Igbo especially outside Igbo land may present to an external observer as disunity, hatred and counterproductive. It takes the ontological exposure of being Igbo, as was undertaken in this research, to understand it otherwise.

Secondly, the wanton disconnection of the Igbo from traditional worldviews, religion, practices has resulted in the erroneous understanding and misinterpretation of the more external activities commonly observed among the Igbo even by the Igbo themselves. Such studies as this, can only help to widen and sustain the gnoseological gap already existent between the average Igbo and the ontological content of being Igbo. Given the above, the present researcher observes that the impact of these previous studies in addressing the existential crisis bedevilling the Igbo nation had been minimal.

As an insider, the present researcher has strongly engaged with numerous Igbo and it could easily be seen that these empirical studies are not set upon a proper ontology which offers the foundation for the interpretation of empirical data. In other words, this researcher goes by the opinion that to properly read the empirical data and correctly analyse them, an accurate consideration of the ontological content of those data is required.

This work, therefore, closes the gap of setting the primary unit of Igbo existential reality on a veritable ontology; this primary unit being the individual. However, very many researchers had been found engaged with the ontological exposure of themes in Igbo existentialism but for whatever reason, majority of Igbo specialists within the broader spectrum of African humanities do not find it expedient to narrow their research down to the Igbo world; they rather remain faithful to Africa, leaving the Igbo microcosm to be located in the macrocosm of African humanities. At this continental level, it is easy to find works in ontology. For instance, the kind of studies undertaken by Placide Tempels on 'Life', Ike Odimegwu on 'Personhood', Barnabas Okolo on 'Being' and so forth, are there to be seen. The present researcher employed the technique of documentary hermeneutics and analysis combined with in-depth library research method of inquiry into the complex composition of the individual in Igbo ethnography and ontology. The individual is not a common theme in Igbo existentialism, but the present researcher observes that even then it is at the centre of other themes that constitute issues in Igbo life. For instance, the issue of social cohesion among the Igbo for which they are understood as hating each other which has been captured earlier as a misconstrue of their competitive reflex, or leadership and politics for which they are understood as having no designated leaders captured in the phrase "Igbo enwe eze" 1 which often recurs whenever contemporary politics requires that the Igbo present a common front and interest. Both ask for further insight into the ontological understanding of the individual; it is this ontology which will set the foundation; shedding light on those other issues that may have been otherwise misunderstood and misconstrued.

This work understands the individual in Igbo ontology as Onweonye. Onweonye contains at the same time the concepts of selfhood and personhood. More than the English language, Igbo language is deeply crafted from immemorial times to convey ontological sense and meaning. Most often, Igbo words are components of being Igbo and connect the Igbo-ness of universal being (the Igbo see the world from the prism of being Igbo whereby being Igbo is conceived as universally applicable). Wherever they are found, the Igbo keep seeking or creating the environment in which the Igbo spirit can thrive. To get to the meaning of Onweonye (unlike the study of personhood and its internal constitution and function), it is ontology, more than psychology, neuroscience, philosophy of the mind, sociology and anthropology which will be our guide. Interestingly, this ontology is not found in any preceding intellectual tradition, since it is not a rationalizing culture which developed through time from epoch to epoch as is found in western or Greek philosophy; rather the ontology is contained in the word itself which conveys the totality of itself and meaning.

This work reviewed some relevant literatures both from Igbo-African studies and western related schemes; it also

\footnotetext{
1 "Igbo enwe eze" is a phrase which derogatorily presents the Igbo as lacking organization and leadership, especially where modern interest-driven politics requires a common front and interest. However, it is meant to underscore the republican and egalitarian nature of the Igbo world which presents a tapestry of multiple colours in opinions, inclinations, goals and aspiration; it is the dynamic force of the progressive Igbo spirit where by monarchical systems are not popular among them in such a way that interests and desires of such institution may constitute laws in society, theirs is rather a universe of competing individuals where competence and expertise are the fundamental qualification for rulership; more or less captains and chiefs.
} 
reviewed methods in the study of ontology so as to narrow down on the techniques and methods adopted by the work. In this work, Onweonye is introduced into the Igbo ontological discourse in an entirely new and insightful manner to give a new perspective and shed light on certain observable social behavioural patterns among the Igbo. The researcher aims at finding a place in the study of ontology for Onweonye as defined by this work through the conventional and contemporary understanding of selfhood and personhood before launching into the subject matter of the research which is to explore the ontological content of Onweonye.

Chuka Okoye took a swipe on the ontological exposure of Onwe. That exposure, following the common pattern of Igbo cosmological discourse, traced the hierarchy of being in Igbo cosmology, which aimed at locating the place of Onwe in the arrangement. He claimed that Onwe is located at the third sphere of the Igbo cosmos, characterized by material existence and interpenetrated by spirit forces. In this sphere, according to him:

We thus see the three categorizations of the self as follows: The Soul - Mkpuruobi; The Spirit- Mmuo; The Body-Aru The trio above constitutes what we call the 'onwe'-self in African (Igbo) thought.[14]

Meanwhile, in his study of the Igbo notion of Man, Edward Uzoma Ezedike made a similar allusion thus:

This is why the traditional African concept of man is conceived as composite of body and soul, not body alone, nor soul alone. The soul animates the body. It is believed that when a man dies, it is the body that suffers disintegration and decomposition, while the soul departs to assume a separate existence. In reality, to the Igbos the terms soul and spirit are synonymous, in spite of the fact that they have a separate word for each namely: Nkpuruobi (soul) and muo (spirit). [15]

E. U. Ezedike's opinion aligns with that of many scholars of Igbo humanities about the position and constitution of man in the Igbo cosmos. The present researcher observes that $\mathrm{C}$. Okoye, in his work, supplanted Mmadu for Onwe and caused the ontological significance of Onwe to be lost in that exercise. Again, Okoye like many others may understand Onwe as the human person which translates to Mmadu, but it should be noted that Mmadu is the essence and existence of the human being, while Onweonye of our rendition is the integral expression of that being, it is both passive and active; both being (secundum esse) and becoming (secundum fiari) and sustains the idea of social gradation. In as much as Mmadu can also be used among the Igbo to express gradation and becoming, like in the expression "O burugo mmadu" to mean "He/she has attained maturity", it is Onweonye which in itself contains and expresses that maturity into the ideal individual.

The work of Ike Odimegwu is worth particular and special review in a research like this because, writing in terms of Africa, without the specific mention of Onweonye, his theory of "Integrative Personhood" cut seamlessly into the ontology of Igbo Self-Personhood in a systematic and detailed manner. Although he did not say Self-Personhood, but it is easily noticeable that he did not isolate the two concepts. Rather,
Odimegwu understood Integrative Personhood as shaped by historical experiences and cultural exigencies. He brought out in a very beautiful way the extrinsic and intrinsic dynamics; the interior and exterior relational essence of the Integrative Personhood in three categories - Individuality, Communality and Presencing. The emergent Integrative person is not worldless and does not exist in an Archimedean point. In his opinion:

In this matrix of consciousness and existence the atomic separation of the individual as an autonomous entity becomes impossible and futile while the communal element of personhood becomes the dominant element of existence and consciousness. [16]

The Integrative Person both shapes and is shaped by the world which Odimegwu referred to as 'Community'. This gives unerring insight into the coming into being and being in the world; it conceptualizes the whole processes of the rites of passage in Igbo culture and underscores the self-person as "being-with". [17] Unlike in the modern conceptualization of the human person in western philosophy, Odimegwu presents the Self-person as "Being in relation" to others, expressed thus:

And so the first consciousness of my self as "I" is acquired in relation to the other. Indeed, one could argue that my consciousness of my self is acquired or derived from my consciousness of your 'self' such that it would seem then that 'I' borrowed my 'self' from your 'self' by your donation of yourself to me; or that this 'I' which I perceive as constituting me is reflected from the you yourself or from the self that is you or in you. [18]

Ultimately, Odimegwu, in exposing the Integrative Personhood, made a compelling ontological case of being in the African context which could be captured as "Being-in-Relation". For clarity and the interest of western minds, it is important not to confuse Odimegwu's Being-in-Relation with Albert Einstein's theory of 'Relativity' While Odimegwu explored the ontic existence of the African Anthropos as 'Ens per existentia', properly located in the area of metaphysics, philosophical anthropology/ontology, Einstein examined 'Res per potentia', located in cosmology and astrophysics. While Einstein dealt with geocentric force represented by the law of gravitation and its relation to physical nature, Odimegwu grapples with an anthropocentric force represented by the integrative personhood and its relation to the universe of others in which the former is the fulcrum of an anthropocentric force. According to Odimegwu:

With other human persons, it is not just a matter of relation of disclosure but the reflection of presence... a relation of mutual inclusion, involvement and interpresencing of presences or loci of being... In this presencing of other persons both my individuality and my communality coalesce to establish my being as being-in-the-community of other persons. [16]

Odimegwu developed what he called the Constitutive Elements of Integrated Personhood which the present researcher understands as the Levels of Consciousness of the Integrative Personhood. In as much as Odimegwu will 
discountenance this position: "This individuality refers to the selfhood of the person; a selfhood that transcends identity in its consciousness of identity and in its incompleteness, and in its presenceing of being," [19] the present researcher understands him as meaning that the personhood of the subject does not indulge in the consciousness of its individuality as is evident in the Cartesian subject. Rather aware of its individuality, it connects intrinsically to others in communality by presencing. Firstly, the Integrative Personhood is conscious of its individuality; this consciousness Odimegwu underscores as basic. This level of consciousness is limited by space and time and extended by circumstances and experience. Secondly, Odimegwu, assigns personhood a location in the community where it operates and functions. This very level of consciousness widely separates his subject from the subject of modern western philosophy. Here, he stressed Jomo Kenyatta's argument: "that the communality of African personhood is not the same thing as the collectivity of individualist personhood." [18] By 'individualist personhood' is meant, the Cartesian or western anthropocentric subject of western philosophy of modernity which exists as independent and disconnected. In communality, the personhood of the subject is offered the loci of operation and function (community) and with a mode and character (communion). At this level also, Odimegwu concretely established Being-in-relation. Thirdly, Odimegwu establishes the consciousness of presencing as consequence of the ontological interaction between individuality and communality. The necessity of communality is predicated upon the inadequacies of neediness and insufficiency which limits the possibility of radical unconnected individuality. Individuality cannot be established outside the communality which is the source and location of being related as individual. For the consciousness of presencing to fully emerge, intendency appears at the intersection to establish reasonability, futurism and intentionality. In as much as Odimegwu is threading the abstract paths of metaphysics, the present researcher can easily relate with his trajectory in practical terms especially as it has to do with being born Igbo and the symbolisms and significance borne by the various rites of passage to ultimately passing into the afterlife and can see how this metaphysics can be concretely established in social anthropology. In as much as Odimegwu did not intend it, like many philosophers before him, it can, at the same time, constitute the fundamental law of physics in as much as the interaction of entities therein generates mobility and action seen yet in human person but could be transferred to inanimate entities in a future time. This is why the present researcher thinks that his manner of ontology corresponds to contemporary method and worth particular attention.

In all these, the establishment of the individual in Igbo ontology as Onweonye is still important and relevant. To relate to these preceding literatures, the present researcher deployed the unusual couplet of self-person which brings together the exterior and interior dimensions of the individual. Onweonye establishes the individual, locates same in the cosmos of varied existence, elucidates its functionality and projects its transformation into another sphere of existence within the same cosmic reality.

\section{Methods in Ontology}

\subsection{Western Ontology}

The present researcher thinks that a work in Igbo/African studies may not avoid at least a marginal view into western studies because their influence on the African mind and scheme of studies is strong. Also, acceptability and reach of research may require that some comparative allusions be made to bring a foreign reader through a familiar terrain into a totally different if not strange area of studies. In line with these thoughts, Greek/Western metaphysics began on the presumption that there is a single element which accounts for the myriad of things in the world. As Peter van Inwagen and Meghan Sullivan puts it: "metaphysics was the "science" that studied "being as such" or "the first causes of things" or "things that do not change"." [20] That singular element has been the quest of western philosophy in different epochs of its development. With Christianity dominating western philosophical culture, it is not surprising then that in the medieval era the former metaphysics of being closed in on God as the first and final cause. It was Thomas Aquinas who championed that cause and saw to it that the former 'Being' Of Aristotle was replaced by the Christian God. From that moment on the being/non-being, existence/non-existence of God has been a contentious issue in that philosophy. The trajectory of the Aristotelian 'Being' continued to change through the course of western metaphysics; mutating and metastasising. Through time, the first/final cause has transited from the 'Being' of ancient Aristotle to the God of medieval Thomas Aquinas and the Man of modern Rene Descartes. When the emphasis shifted to 'Man' as the absolute 'Subject' in modern philosophy and 'Mind and Body'; 'One and Many' introduced as central issues in metaphysics, the ancient-medieval consensus and metaphysical homogeneity began to deplete such that today, the above defining quest can no longer stand true as the description of metaphysics. Contemporary western metaphysics has become multi-thematic; concerning itself even with materiality and physics unlike before. Causality which used to be the singular concern of metaphysics, illustrated in terms of 'Cause and Effect' is now viewed from a relational perspective. Western metaphysics now concerns itself with causal relations.

\subsection{Igbo/African Ontology}

On the one hand, Placide Tempels may have laid the foundation of studies in African Ontology in his work: $L a$ Philosophie Bantoue (1945). In that work, Tempels was engaged with Being and Force; their relationship and place in the African universe. Through distinct existence, Tempels came to complimentary existence and finally arrived at identical existence of Being and Force. [21] This may have introduced an era of cosmological discourses which aped the manner of western philosophy asking the fundamental 
question of the primary constitution of the world. The Ethno-philosophy of Paulin J. Houtondji and Alexis Kagame explored the belief systems, hierarchy of beings, myths, legends and folklores in African cultures. This method thrived for a long time and presented African Ontology as homogeneity. As would be expected, many Western-trained African philosophers had adopted this western ancient and medieval method of doing ontology in their study of Africa and Igbo universe of things, which has created its own limitations in exploring African/Igbo ontology. On the other hand, Igbo ontology, properly addressed, is not an anthology in systematic disputations on the ultimate cause like we see in western metaphysics; it is not an epochal unveiling of the concealed nature of being requiring the rational or empirical efforts to be known. Rather, it is the insightful, intuitive and guided reading into the mysteries, symbolisms and patterns in nature and things to adduce their interconnectivity with human life and existence. It was Bona Christus Umeogu who typified this method of studying Igbo ontology. In his study of ' $O j i$ Igbo', he had stated: "The evolution of both science and arts followed a unique and consistent pattern in (the) understanding the changing nature of matter and the universe especially in understanding its true essence in man's life considering his prevailing circumstances and environment." [4] Celestine Mbaegbu, in studying the hierarchy of beings in Igbo world view, posited that such study will make "non-professionals in African philosophy to grasp better what Igbo Ontology is all about." [22] However, shortly, in what seemed like a swift drift, he averred:

Igbo metaphysics or Ontology on the one hand, restricts its enquiries to the Igbo man and his presence in the world and world view. The topics that constitute a special field of study here include: the nature of ultimate reality for the Igbo, the nature of beings or "forces according to Tempels, in the Igbo universe, the relationship between the sensible and the supersensible beings, that is, their interaction; others are hierarchy of beings in the Igbo universe, laws of vital causality, etc. [22]

In this shift of emphasis, Mbaegbu expanded the horizon of Igbo metaphysics but was unwilling to plunge into that far-reaching point in his discourses on God. He clearly waded his way through the clustered path of Igbo spirits, methodically trailing the western scheme of the world. Meanwhile, Ike Odimegwu, before him, had deviated from that manner of doing Ontology but was concerned with an 'African' perspective, not Igbo. Nevertheless, his method of Ontology agrees with the contemporary manner of doing Ontology, both in the west and elsewhere, which opens up African ontology as an interaction of opinions, ideas, hypothesis, theories and postulations. Unlike Odimegwu, the present work narrows down to Igbo Ontology, at the same time, like Odimegwu, agrees with the contemporary manner of doing Ontology combined with the method of morphological insights as represented in the works of Bona Christus Umeogu.

$\mathrm{Be}$ that as it may, Igbo ontology is pervasive; it deals with the intrinsic and extrinsic elements that constitute the Igbo universe, culture, life, beliefs and hopes. The Igbo universe itself is not merely empirical and physical; it is interpenetrated with invisible forces always felt in palpable ways. Igbo ontology is written in the Igbo universe in the forms of symbols and practices and could be gleaned from everyday life, especially in communication. This is another new dimension the present researcher has brought into the discussion of Igbo ontology. Therefore, its corresponding Ontology is not written in books, but in the universe itself and is represented in everyday communication. Igbo ontological concepts are not arbitrary words or derivatives from other languages; they are core-Igbo expressions of the world and experiences thereof. Such concepts contain in themselves the totality of the ideas and realities which they express. To understand the ontological contents of Igbo concepts, there is need to undertake an exercise in the morphology of words. Here is not meant the inflectional morphology but the formational morphology through analysing the component parts of the words and their possible meanings. It is also important to examine the contextual usages and applications of the ideas they connote and correlate in the function and operation of the Igbo universe. Knowing also that the Igbo $A f a$, to a large extent, preserved primordial ontological concepts in a demotic language, students of Igbo Ontology may also acquaint themselves with $A f a$ to be able to penetrate the Igbo universe of meaning. In this research, we will be engaged in the formational morphology of words; exploring the phenomenology of their disclosure in ethnological variations and functional hermeneutics.

\section{The Ontology of Onweonye}

Onweonye is a composite word made up of 'Onwe' (loosely 'Self') and 'Onye' (loosely 'Person'). In other words, Onweonye could loosely translate as 'Self-Person'. Remarkably, personhood and selfhood could be treated in isolation of each other in western thought. On the other hand, in the integral/profound expression of individuality in Igbo, Onwe and Onye cannot exist in isolation in Igbo understanding of "Mmadu" (human being). Both together constitute the integral/profound expression of "Mmadu" as an individual in the universe of other entities. Therefore, Onweonye is the integral/profound expression of the essence of the Igbo existential being. Onweonye is a concept which encompasses the pivotal idea in the understanding of Igbo attitude towards life and living. Onweonye has no corresponding transliteration in English, and in portraying the internal and external dimensions in the functionality of the individual, Igbo use it as one word, not a couplet. To render the compound word properly in English, it has to be separated into "Onwe" (Self) and "Onye" (Person). Consequently, Onweonye can directly translate only as Self-person.

\subsection{Formational Morphology and Ontological Content of Onwe}

Onwe can easily be transliterated as "Possessor"; it is the noun form of the verb "Inwe" (to possess). The verb root "Nwe" 
simply means "Possess". The present researcher acknowledges that this transliteration might be off-putting to even an expert of the Igbo language because it is entirely a new perspective. This is precisely the new dimension this research work is bringing into the discussion, to explore the formational morphology of the word in the hypothesis that every Igbo concept is generative of its ontology from within itself. In other words, the functionality of the self in Igbo understanding is characterized by possession. The idea of this possession connotes and correlates with being in-charge and in-control of one's life. Onwe is the absolute self-seeking and self-centred individual. It could be said that the reason and purpose of the world is Onwe and the world itself revolves around Onwe. The capacity of the Igbo Onwe is limitless; it aims at possessing the world and all it contains.

Onwe is the Igbo counterpart of the Cartesian "I" which does not acknowledge the relevance and influence of the other, but has the inexhaustible capacity for individual existence. They both are conscious of their "Being and Existence". The difference is that whereas the Cartesian "I" is characterized by thinking, the character of the Igbo Onwe is possessing, taking charge and controlling, with thinking as tool; whereas the Cartesian "I" exists isolated on an Archimedean point, thinking its thinking self. The Igbo Onwe is deeply conscious of the universe, the only area of its operation of essential being as in-charge, in-control and in-possession.

Ethically, Onwe operates a kind of Kantian morality of 'Categorical imperative', , but it is also diametrically opposed to slavery. In Kantian morality, it is the Will which drives the individual more than reason, but in as much as that irrational Will is a compulsion about which the Kantian individual exercises no control, it imposes itself on its immediate environment as master. Nevertheless, that individual is a self-authenticating and self-legislating subject. Onweonye contains that Will which internally mechanizes its operations only that it is not self-authenticating and self-legislating. The Kantian subject is the slave of the Will and not to another; Onweonye is its own master and cannot be enslaved by another. More succinctly, Onwe embodies the inherent duty to possess and not be possessed by another. Therefore, Onwe is the force behind Igbo industry and enterprise; it is the force that subjects the universe to the Will of the individual; it is the resolute and invincible Will which aids the Igbo in his engagement with the universe.

What then does the possessor possess to attain the status of a possessor? The Igbo does not think of this possession as materiality alone. In the Awka area of Igbo land, there exists the idiomatic couplet "Ife akuaku na ife enwe enwe", which distinguishes materiality from non-materiality in terms of possession. While "Ife akuaku" stands for material possession like money and estate, "Ife enwe enwe" represents non-material possession like extended and extensive

2 'Categorical Imperative' is the deontological theory of Immanuel Kant expounded in his Metaphysics of Morals (1785). It stands for a compulsive moral obligation binding on the individual over which the individual is incapacitated to exercise reason. Kant's morality has been understood as 'Slave morality' in which the individual operates irrational will. relationships, reputation/good name and interconnections of entities. Another couplet that suggests what the possessor possesses is "Aku na Uba". "Aku na Uba" is the full content of the life quest of Onwe. Again "Aku na Uba" is materiality and non-materiality; while " $A k u$ " represents materiality like quantifiable wealth, "Uba" is the non-material (family lineage, extensions and connections) content of Onwe's possession. This couplet ordinarily transliterates as richness, wealth or affluence, but it is only " $A k u$ " which is measured by the quantum of one's finances and estate. Aku relates to $O k u$ (materials appropriated through hard work, especially livestock) $I k u$ (to engage in enterprise especially verifiable work) On the other hand, "Uba" is reckoned by one's reach in connection, extension, relevance and influence. Therefore, in the Igbo socio-economic universe, "Aku" without " $U b a$ " is a moral deficit; whereas "Uba" without " $A k u$ " is not a deficit and is preferable, but in many instances not possible because "Aku" by necessity beckons "Uba" and the Igbo socio-economic environment is by default designed to sustain the inseparability of " $A k u$ " and "Uba". Yet in terms of their relationship to Onwe, "Aku" takes chronological precedence to "Uba" while "Uba" exercises precedence to "Aku" in ontological hierarchy. At the full disclosure of Onwe, it is "Aku na Uba" and "Ife akuaku na ife enwe enwe" which best describes the content of possession. It is important to note, that "Aku na Uba" and "Ife akuaku na ife enwe enwe" is the singular objective for all Igbo struggles, industry and enterprise. In their engagement with the larger society, it is the enabling environment to meet this life aspiration which informs their idea of a working society. In their migrations and settlements, it is that environment of their meaningful engagement with life that they continually seek. They can settle anywhere in the world that offers that environment or the hopes of it.

\subsection{Formational Morphology and Ontological Content of Onye}

Onye can be transliterated as "Giver". It is also the noun form of the verb "Inye" (to give). The verb root "Nye" simply means "Give". Onye is rendered as 'Person' in English parlance. However, Onye is much more than Person. While person is an existential entity open to the various categorizations of neuroscientists, philosophers of the mind, psychologists and social anthropologists, based on the perceived operations and functions of the masked mind; Onye ontologically presents with a specific function and operation sustained in the web of a well-structured moral imperative and socio-economic sphere. The Igbo individual is internally structured to give. However, what is given is measured by the quantity and quality of material and non-material possessions of Onwe. Onye underlines the indebtedness of the Igbo to the Other; this Other includes entities other than Onye, humans and things, living and dead, created and non-created. The Igbo spends a lifetime struggling and making efforts to pay these debts as due within the expectation that one may possibly liquidate that debt. This intrinsically inherent debt is owed by parents to children and vice versa, by progenies to progenitors 
(ancestors) and vice versa, by mortals to immortals and vice versa etc, making the Igbo universe a web of interconnected debt repayment. The average Igbo exercises entitlement consciousness to this repayment and in many ways demands it to the extent Onye's repayment capacity is perceived. The entitlement consciousness is predicated on a moral demand and is essentially opposed to begging; no Igbo delight in receiving from another as a beggar or are comfortable to be referred to as the receiver in the manner of beggar. In the words of Olaudah Equiano, an Igbo slave who wrote an account of his sojourns in a work first published in 1789: "we are all habituated to labour from our earliest years... and as we are unacquainted with idleness, we have no beggar." [23] There are no beggars in the pristine Igbo socio-economic milieu and those in any way incapacitated to afford their means are taken care of within that web of giving. Such people are referred to as Ogbenye, which is another composite word. "Ogbe" means "Community" and "Nye" means "Give". In other words, it is the responsibility of the community, within a moral encoding sensitive to hurting their pride as Onye, to give such persons. Meanwhile such a state is circumstantial and temporary from which the individual or individuals involved are expected to extricate themselves as quickly as possible. The community is made up of individuals who are internally wired to give. It is this sense that sustains the functionality of the Igbo social, economic, moral, religious and cultural universe.

\subsection{Ontological Derivation of Onweonye}

Onweonye is the Igbo understanding of the individual. It is both the essence of being and existential becoming. In other words, Onweonye is at the same time what the individual is and what the individual constantly becomes. It represents the internal constitution and external functionality of the individual. The composite word Onweonye literally transliterates as the possessor of the giver. Consequently, it is possession which takes ontological precedence in the being and becoming of the individual because "Onyeonwe" is a reverse morality and a negation in understanding the Igbo ontological Subject (Individual). The full-fledged Igbo individual possesses the capacity and power of an ultimate possessor/giver - Onweonye. In common folk language, words like "Ima onweonye", "Inwe onweonye", "Ibu onweonye" feature. Ima onweonye is used for Self-knowledge/awareness/consciousness; it is the gnoseology of self-person, sometimes used derogatorily as selfishness. Inwe onweonye is the ultimate possession of the full capacity/potentials of possessor/giver, loosely translated as "Independence". Clearly, the Igbo have an integral, profound and deep sense of independence as the ultimate possession of the individual whereby it cannot possibly be possessed by another. This gives insight into the difficulty of subduing the Igbo even in the condition of slavery. The essence of individuality is to ultimately possess the possessor-giver power by which one cannot and can never be possessed by another and is not compelled by conditions to receive from another. The story of Igbo Landing, a historic site at Dunbar Creek on St. Simons Island, Glynn County, Georgia, is a veritable demonstration of that deep Igbo sense of independence. In 1803, a group of about seventy-five Igbo slaves bought to be resold in St Simon Island, marched into the marshy waters and drowned themselves. There are no accurate records as to the number of victims or the full picture of what happened. Yet it is known that they seized the vessel, drowned their captors and committed mass suicide. According to Samuel Momodu: "the deaths signaled a powerful story of resistance as these captives overwhelmed their captors in a strange land, and many took their own lives rather than remain enslaved in the New World." [24] Inwe onweonye is the beginning of a purposeful life and perfect existence. Ibu onweonye could be translated to mean self-confidence/composure, like the English phrase "To be oneself'. In this sense, Onweonye is a state of being or condition of the mind. Onweonye paves the way into understanding the Igbo attitude towards life and gives clue about the social behaviours of the Igbo especially those patterns for which they are stereotyped as greedy, arrogant, boastful, loud, proud and disrespectful and so on. It is not only that the Igbo universe is by default structured to enhance the thriving of the individual as Onweonye, but that the Igbo also understand that default structure as universally applicable; wherever it is not found, they struggle to institute it.

As have been said earlier, Onweonye is both a state of being and becoming. On the one hand, Onweonye is a state of being in the sense that the Igbo individual can only be ontologically described by abstraction as Onweonye even though not all individuals can operate the full functions of Onweonye as have been described above. Notably, unlike the western understanding of self and person, Onweonye is not known only through its functions and operations. On the other hand, Onweonye is a state of becoming in the sense that the Igbo engages in and undertakes from birth to death, through rites, initiations and practices, various epiphanies of Onweonye. In other words, the various moments in the Rites of Passage in Igbo socio-cultural practices depict the momentary unconcealment of Onweonye. Here also the position of Ike Odimegwu comes alive. In his tripartite categories of Individuality, Communality and Presencing, he not only showcased the operations and functions of personhood in a defined environment, but also inadvertently portrayed the trajectory whereby the individual is born into the community where he lives from an epochal-temporal existence into an eternity of presencing. That way his work can conceptually ground the rites of passage in Igbo culture. For the interest of readers trained in western conceptual schemes, in these epochal-temporal manifestations of Onweonye, it is the Phenomenology of Martin Heidegger which comes close to the understanding of the knowability and unknowability of Onweonye through concealment and unconcealment within the process of the Rites of Passage. In Heidegger's Phenomenology, Phenomenon is "that which shows itself in itself"; a concealment and unconcealment. Phenomenon exists in a dynamic process of showing itself and cannot be known except it is uncovered. In the analysis of Jani Koskela: 
For Heidegger, the appearance of a thing and the thing itself are interconnected, and moreover, are one and the same. In this sense, phenomenology is seeking after a meaning, which is in the entity's mode of appearing. But things do not appear themselves. They are uncovered to someone. Thus uncovering pre-requires not only what is being uncovered, but also another being this being is uncovered to, i.e. human being. [25]

The Phenomenon in Heidegger's terms is Dasein. Dasein is an appearance and a disappearance, a concealment and unconcealment, there and not there, in an endless process to be known by another, but abundantly known by its self unconcealment to itself. Nevertheless, Onweonye does not suffer the ontic isolation of Heidegger's Dasein - "an entity which does not just occur among other entities. Rather it is ontically distinguished by the fact that in its very Being, that Being is an issue for it." [26] To illustrate the significance of Onweonye in Igbo socio-cultural arrangement, it is important to encounter how this ontology is reflected in real life, more than being a subject of intellectual exercise. At every stage in the Igbo Rites of Passage, it is status which is unconcealed. That status is the unconcealment of Onweonye. Yet since the individual is still in the process of self-realization, it is in the clearing of the next stage in the rites of passage will Onweonye reappear to be known and yet concealed as yet to be known. For instance, the people of Obowo in Imo Sate, Nigeria, have the ceremony of Iwa Akwa in their Rites of Passage which signifies coming of age of the male folks; initiating them into the ontological hierarchy of Onye. In that ritual the matured adult is unconcealed as okorobia/dimkpa while Onweonye is concealed. Yet it is Onweonye which sheds light on the depth of the ritual. The Individuals are presented as full-fledged adults (Okorobia/Dimkpa), but is actually the responsibility of Onweonye that they take on; even at that, they are still in the process of becoming Onweonye of another level in the hierarchy of being in Obowo. Onweonye is being and becoming, essence and existence of the individual.

However, Dasein is conflicted in its fragmentation. In the development of the idea of human individuality in western ontology, it was Frederick Hegel who eventually identified this conflict. In his Phenomenology of Consciousness, Hegel traced the historical development of the human spirit from sensitive consciousness to absolute consciousness. The Absolute Spirit (Consciousness) of Hegel corresponds with the conscious subject espoused by Immanuel Kant in his Critique of Pure Reason. But unlike Kant, Hegel recognized the existence of the "Other". In other words, the individualized and individuated consciousness is not alone in the universe of loneliness, but that the universe is peopled by identical entities like itself. At the same time, the Absolute Spirit exercises the Will to overcome, necessitating conflict as the only dynamics in entitative interaction/relationship. According to Michael Inwood:

Hegel is more aware than Kant that a self-conscious being is an embodied living creature as well as a bare 'I think', but it must be willing to risk the loss of its biological life in the defence of its objective authority. [27]
No wonder he has to develop the dialectic which proves to be the only method by which the absolute Spirit can function in the universe of others. This dialectics will eventually be materialized by Karl Marx, Edmund Husserl and Jean Paul Sartre. Tim avers:

The method developed by Hegel is that the dialectic of contradictions and exceed via a new phase of the synthesis. This dialectical method will be decisive in the history of philosophy and influence Husserl, Sartre and especially Marx, who thinks the economic and social history in terms of the Hegelian dialectic. [28]

Interestingly, Onweonye also corresponds to the sensitive consciousness of Frederick Hegel. However unlike the sensitive consciousness, it is not in a process of evolution, but in a process of disclosure and unconcealment. The integral ontology of Onweonye as essence and existence, being and becoming, concealed and unconcealed, known and unknown is immutable by the dynamics in epochal-temporal epiphany.

\section{Conclusion}

Onweonye contains the ontological significance of the individual in the Igbo universe both as essence and existence, being and non-being, being and becoming. It is at the same time selfhood and personhood. As self, it is the individuating principle and as person, it is the individualizing principle. The Igbo-ness of Onweonye is its location in the universe of other entities made up of the living and the dead, living and non-living things, visible and invisible elements. It is not possible for entities to exist in isolation in the Igbo universe; there is always interconnectedness and interpenetration of entities; a web of existence that includes unseen and invisible forces and beings. Onweonye functions and operates in this web of relationship. If it functions and operates like Master, it does not perceive a universe of things; it is aware of a living universe of varied and enormous forces in which its integral/profound expression as Onweonye brings about harmony and balance. Harmony and balance is the whole purpose of human engagement with the universe in Igbo cosmological thought. Onweonye comes close to the understanding of self and person in western philosophy of the mind, neuroscience and psychology only in terms of functionality. While functionality is at the centre of western understanding of the self and person which are isolated from the world of others where they exist as abstraction, their operations necessarily generate conflicts. Onweonye in its interconnectedness and interpenetration in a universe of other entities and in an unbroken chain of concealment and unconcealment does not generate conflict. Its affirmation and negation are composite and complementary in opening Onweonye to be known.

Onweonye could relate to the concealment and unconcealment of Heidegger's Dasein, and contrasts with the conflicted Hegelian Absolute Spirit. Even in its correspondence to Dasein, its disclosure and unconcealment is a gnoseological not evolutionary process (either in a Hegelian or Darwinian sense). In the process of unconcealment, it is 
moments of existential conditions that are perceived while the concealed Onweonye thrives in the dynamics of continuous disclosure. Its ultimate unconcealment corresponds with being translated into a spiritual entity, reverting back to the universe to be part of its life. This happens at the end of material existence which does not extinguish life, but rather transforms mode. The transiting spirit is still part and parcel of the Igbo universe which does not lose its identity as Onweonye. In its contrast with the Hegelian Absolute Spirit, Onweonye does not conflict with other entities of the Igbo cosmos, it interconnects and interpenetrates them in a relationship of complement to bring harmony and balance about.

In the Igbo universe, Onweonye is the individual characterized in this work as possessor and giver. As possessor, it energizes the egalitarian Igbo universe in which industry and enterprise define ones level in the social stratification; that egalitarian state is proved by the universality of Onweonye whereby no individual is downtrodden or worshipped by another. Onweonye makes every individual their own champion and boss; and no one is subservient to another. As giver, it sustains the vivacious Igbo universe in which all access means of survival without denigration or debasement. It assures the redistribution and availability of resources while everyone's pride is protected. Finally, it guarantees the survival of the Igbo race into eternity. It is important to note, that the Igbo do not operate an exclusive universe, but envisages a world in its own schemes which spreads from the nucleus of the Igbo centre; not necessarily operated from the fulcrum of the Igbo pivotal centre; another way of saying that the Igbo perceives the world as essentially Igbo in character, but that world is inhabited by a variety of races, languages and culture and yet does not compromise being Igbo. Onweonye is the self-personhood which lumps together all aspects of Igbo existential realities and ideals, being and becoming.

In spite of this integral individuality of Onweonye, in daily living, the Igbo do not manifest Onweonye in a stride. It is either Onwe or Onye which is mobilized in one stride of action. In the expression of Onwe, the Igbo is misconstrued as selfish, greedy, domineering, ruthless; and if the heat of exercising Onwe is among the Igbo or between two Igbo, they are misconstrued as hating each other, lacking leadership and unpatriotic. This work rather asserts that it is the internal drive to possess, even the whole universe powered by the Will as contained both in the Igbo genetic composition and socio-cultural environment that is at play. In the expression of Onye, the Igbo are misconstrued as proud, loud, vain and cavalier. It should be noted that the qualitative and quantitative expression of Onye gives the Igbo an earned place in the socio-cultural environment. Many who have discussed title taking in Igbo culture; the likes of Ogechukwu A. Ikediugwu [29] and Thomas M. Landy [30], may have tarried in the peripheral thought that the Igbo crave for titles. This work asserts that it is rather the interior compulsion of the Igbo to fulfil the ontic drive of Onye, by which one gives back to the community of humans, which underlies the quest after belonging to institutions; title is to certify that belonging.
Therefore, expressing Onye to merit a desired and deserved place could be misconstrued as egotistic and diminishing of others. This work delved into this ontological exposition to offer a dimension and prism through which the Igbo may be viewed whenever they are exhibiting certain social behaviours which have earned them hatred and attacks in the past. This ontology is an introduction of Onweonye - the self-personhood of the Igbo individual which beckons discourses in Igbo ethics.

\section{References}

[1] Arinze, F. A. (2008). Sacrifice in Igbo Religion, Onitsha: St. Stephen's Press.

[2] Ifesieh, E. I. (1989). Religion at the Grassroots (Studies in Igbo Religion), Fourth Dimension Publishing.

[3] Metuh, E. I. (1985). African Religions in Western Conceptual Schemes: The Problem of Interpretation (Studies in Igbo Religion), Ibadan: Claverianum Press.

[4] Umeogu B. C.; Onebunne, J. I.; Ojiakor C. I.; Etodike C. E. (2020) "Kolanut and Symbolismic Universe: Towards the Creation and Constitution of Igbo Science and Arts," Canadian Social Science, 15 (4), pp. 1-6 DOI: 10.3968/10983.

[5] Mbaegbu C. C. A. (2012). Hermeneutics of God in Igbo Ontology, Awka-Nigeria: Fab-Anieh.

[6] Asonye, E. (2013). "UNESCO Prediction of the Igbo Language Death: Facts and Fables", Journal of the Linguistic Association of Nigeria, 16 (1\&2), pp. 91-98.

[7] Akande, S. (2018), "5 popular stereotypes about the Igbo people”, in Pulse. ng October 5. 2018, retrieved September 18, 2020, from

https://www.pulse.ng/gist/tribalism-5-popular-stereotypes-abo ut-the-igbo-people/hn8vyxw.

[8] Adebowale, S. (2016). "How Ndigbo defeated Buhari's CBN Igbo Trade Strangulation Policy, by Intersociety", Eagle, January 12, 2016, retrieved September 19, 2020, from https://theeagleonline.com.ng/how-ndigbo-defeated-buharis-c bn-igbo-trade-strangulation-policy-by-intersociety/.

[9] Ezeakukwu, N. E. (2019). "The Marginalization of the Igbo People in Nigeria's Political and Economic Sectors: What Is the Way Forward?" Open Journal of Social Sciences, 7, 427-437.

[10] Iherue, O. S. (2011). "Causes and Effects of Moral Decadence in Igboland: Socio-Political, Economic and Religious Perspectives", Unpublished PhD Dissertation submitted to the Department of Religion and Cultural Studies, University of Nigeria, Nsukka.

[11] Nwoye, C. M. A. (2011). "Igbo cultural and religious worldview: An insider's perspective", International Journal of Sociology and Anthropology, 3 (9), pp. 304-317.

[12] Ibiwoye, D. (2013). "Igbo have no leaders - Ben Obi," Vanguard, January 26, 2013, retrieved September 19, 2020, from https://www.vanguardngr.com/2013/01/igbo-have-no-leadersben-obi/. 
[13] Marshall, D. and Brian W. (2018). "Intrinsic vs. Extrinsic Properties", The Stanford Encyclopedia of Philosophy (Spring 2018 Edition), Edward N. Zalta (ed.), URL = $<$ https://plato.stanford.edu/archives/spr2018/entries/intrinsic-e xtrinsic/>.

[14] Okoye, C. (2011). “'Onwe': An Inquiry into the Igbo Concept of the Self", Ogirisi: a new journal of African studies, 8, p. 54.

[15] Ezedike, E. U. (2019). "The Concept of Human Person in African Ontology: A Critical Reflection on the Igbo Notion of Man," African Research Review, 13 (2), 54, DOI: http://dx.doi.org/10.4314/afrrev.v13i2.11 P. 133

[16] Odimegwu, I. (2008). Integrative Personhood: A Communalist Metaphysical Anthropology, USA: Transaction Publishers, p. 123.

[17] Okolo, C. B. (1982). What is to be African, Enugu Cecta.

[18] Odimegwu, I. (2008). Integrative Personhood: A Communalist Metaphysical Anthropology, USA: Transaction Publishers, p. 119.

[19] Odimegwu, I. (2008), Integrative Personhood: A Communalist Metaphysical Anthropology, USA: Transaction Publishers, p. 118.

[20] van Inwagen, P. and Sullivan, M. (2020) "Metaphysics", The Stanford Encyclopedia of Philosophy (Spring Edition), Edward N. Zalta (ed.), URL = $<$ https://plato.stanford.edu/archives/spr2020/entries/metaphysi $\mathrm{cs} />$.

[21] Tempels. P. (1945). La Philosophie Bantoue, Belgium: Lovania

[22] Mbaegbu, C. C. A. (2012), Hermeneutics of God in Igbo Ontology, Awka-Nigeria: Fab-Anieh, p. 120.
[23] Equiano, O. (1996). Equiano’s Travels (Paul Edwards, Editor), Heinemann, p. 7

[24] Momodu, S. (2016). "Igbo Landing Mass Suicide (1803)", Black Past, October 25, 2016, retrieved June 22, 2020, from https://www.blackpast.org/african-american-history/events-afr ican-american-history/igbo-landing-mass-suicide-1803/

[25] Koskela J. (2012). “Truth as Unconcealment in Heidegger's Being and Time', Minerva - An Internet Journal of Philosophy, 2012, 16, pp. 117-18.

http://www.minerva.mic.ul.ie/vol16/Heidegger.pdf

[26] Heidegger, M. (1962). Quoted in Jani Koskela (2012), "Truth as Unconcealment in Heidegger's Being and Time', Minerva An Internet Journal of Philosophy, 2012, 16, pp. 117, http://www.minerva.mic.ul.ie/vol16/Heidegger.pdf

[27] Inwood, M. (Review) (2011). Robert B. Pippin, "Hegel on Self-Consciousness: Desire and Death in the Phenomenology of Spirit", Notre Dame Philosophical Reviews, retrieved June 24, 2020, from https://ndpr.nd.edu/news/hegel-on-self-consciousness-desire-a nd-death-in-the-phenomenology-of-spirit/

[28] Tim (2013). "Phenomenology of Spirit by Hegel (Summary)," Philosophy \& Philosophers, retrieved June 24, 2020, from https://www.the-philosophy.com/phenomenology-spirit-hegelsummary.

[29] Ikediugwu, O. A. (2015). "Ozo Title in Igboland as a Negation of Justice and History: an Analysis of Amechi Akwanya's Orimili", Unizik Journal of Arts and Humanities, 16 (1), https://www.ajol.info/index.php/ujah/issue/view/13038

[30] Landy, T. M. (2020), "Initiation, title-taking, and the stages of life in Nigeria's Igboland" Catholics and Cultures, https://www.catholicsandcultures.org/initiation-title-taking-an d-stages-life-nigerias-igboland. 